\title{
Hepatitis E Virus Cross-Reactivity and False-Seropositivity: Challenges to Diagnosis
}

\author{
Mohammad Khalid Parvez ${ }^{1 *}$ and Rana $\mathrm{Ali}^{2}$ \\ ${ }^{1}$ Department of Pharmacognosy, King Saud University College of Pharmacy, Riyadh 11451, Saudi Arabia \\ ${ }^{2}$ Al-Mohammadia Medical Center, Riyadh 11563, Saudi Arabia
}

Keywords: HEV; Hepatitis E; HEV IgG; HEV IgM; Cross-reactivity; False-positivity

Hepatitis E Virus (HEV) infection is generally manifested by a self-limiting acute hepatitis $\mathrm{E}$ and in some cases, by fulminant hepatic failure [1]. Hepatitis E may be symptomatic or asymptomatic with an overall fatality rate of about $2 \%$ worldwide [2]. HEV is an emerging pathogen that has recently evolved to cause chronic liver infections as well as neurologic signs and symptoms $[3,4]$. Recently, an interesting case of acute hepatitis E, concomitant with rash and arthralgia has been reported, too [5]. Post-viral rashes, arthralgias or Adult-Onset Still's Disease (AOSD) are known to be triggered by many herpes viruses, adenoviruses, enteroviruses, retroviruses, paramyxoviruses, including rubella and hepatitis viruses (HAV, HBV and HCV) [6]. Previously, an association of acute polyarthritis with hepatitis $\mathrm{E}$ has shown evidence for past immunization against herpes viruses, like Cytomegalovirus (CMV) and Epstein-Barr virus (EBV) [7].

The proper and timely diagnosis of hepatitis $\mathrm{E}$ is technically very challenging. In the absence of an approved algorithm, the consistency of serological tests and viral load (HEV RNA) quantification in terms of sensitivity and specificity are the limiting factors. In acute hepatitis E, HEV-IgM and -IgG rise simultaneously in the narrow window of detectable viraemia. Furthermore, HEV-IgM false-positive reactions against EBV and CMV have been shown previously [7]. Very recently, a retrospective analysis of HEV serology of 1423 samples has shown a high degree of EBV and CMV cross-reactivity where approximately $33.3 \%$ and $24.2 \%$ of HEV-IgM positive samples were also positive for EBV- and CMV-IgM, respectively [8]. Of these, while only four HEVIgM positive sera showed HEV RNA, indicating true positivity, three demonstrated cross-reactivity against EBV. Only 13.3\% of samples with HEV-IgMseropositivity were HEV RNA positive that highlighted a low positive predictive value of serological testings.

Notably, in the recent report by Al-Shukri et al. [5], though the patient's serology has revealed markers of past infections with CMV and EBV, neither the age of herpes infection nor the history of high fever, rash, arthralgia or AOSD-like symptoms, if any, were mentioned. While the time-related occurring and simultaneous recovery of the two illnesses did indicate a unique manifestation of HEV, a fortuitous or indirect association of rash and arthralgia with post-herpes infection in the patient could not be ruled out. It might be very possible that the clinically silent or asymptomatic illness that was actually initiated by CMV or EBV in the past was reactivated by HEV later.

In sum, ample of HEV false-positive results due to EBV-and/or CMV-IgM cross-reactivity has indicated that serology is unreliable in the diagnosis of acute hepatitis E. Therefore, the diagnosis of HEV infection should be based on clinical presentations raised liver transaminases, serology, as well as confirmatory viral RNA testing.

\section{References}

1. Purcell RH, Emerson SU (2008) Hepatitis E: an emerging awareness of an old disease. J Hepatol 48: 494-503.

2. Aggarwal R, Naik S (2009) Epidemiology of hepatitis E: current status. J GastroenterolHepatol 24: 1484-1493.

3. Parvez MK (2013) Chronic hepatitis E infection: risks and controls. Intervirology 56: 213-216.

4. Parvez MK (2014) Hepatitis E virus-associated neuropathy: an emerging extrahepatic manifestation. Future Virol 9: 1-4

5. Al-Shukri I, Davidson E, Tan A, Smith DB, Wellington L, et al. (2013) Rash and arthralgia caused by hepatitis E. Lancet 382: 1856

6. Serratrice J, Disdier P, Colson P, Ene N, de Roux CS, et al. (2007) Acute polyarthritis revealing hepatitis E. ClinRheumatol 26: 1973-1975.

7. Bento DP, Tavares R, Baptista Leite R, Miranda A, Ramos S, et al. (2010) Adult-Onset Still's Disease and cytomegalovirus infection. ActaReumatol Port 35: 259-263.

8. Hyams C, Mabayoje DA, Copping R, Maranao D, Patel M, et al. (2014) Serological cross reactivity to CMV and EBV causes problems in the diagnosis of acute hepatitis E virus infection. J Med Virol 86: 478-483.

*Corresponding author: Mohammad Khalid Parvez, Assistant Professor Department of Pharmacognosy, King Saud University College of Pharmacy, PO Box 2457, Riyadh 11451, Saudi Arabia, Tel:+966-14675132; Fax: +966-14675133; E-mail: Khalid_parve@yahoo.com

Received February 17, 2014; Accepted February 18, 2014; Published February 25,2014

Citation: Parvez MK, Ali R (2014) Hepatitis E Virus Cross-Reactivity and FalseSeropositivity: Challenges to Diagnosis. J Liver 3: e109. doi:10.4172/2167 0889.1000 e109

Copyright: (c) 2014 Parvez MK, et al. This is an open-access article distributed under the terms of the Creative Commons Attribution License, which permits unrestricted use, distribution, and reproduction in any medium, provided the original author and source are credited. 